Supporting Information to the paper

\title{
Shape-anisotropic polyimide particles by solid-state polycondensation of monomer salt single crystals
}

By

Konstantin Kriechbaum $^{1, a}$, D. Alonso Cerrón Infantes ${ }^{1, a}$, Berthold Stoeger ${ }^{2,3}$ \& Miriam M. Unterlass, ${ }^{1, *}$

${ }^{1}$ Technische Universität Wien, Institute of Materials Chemistry, Department of Applied Inorganic Synthesis, Getreidemarkt 9/BC/2, A-1060 Vienna, Austria.

2 Technische Universität Wien, Institute of Chemical Technologies and Analytics, Department of Structural Chemistry, Getreidemarkt 9/164, A-1060 Vienna, Austria.

${ }^{3}$ X-Ray Center, Technische Universität Wien, Getreidemarkt 9, A-1060 Vienna, Austria.

${ }^{a}$ Both authors contributed equally.

Corresponding author: miriam.unterlass@tuwien.ac.at

Contents:

1 Materials and Methods 2

a. Chemicals and Experimental Details $\quad 2$

- chemicals 2

- gel-growth of the monomer salt 2

- solid-state polymerization of the monomer salt to PPPI 2

- synthesis of PPPI by classical polycondensation 2

b. Characterization Techniques 2

- FT-IR-ATR 2

- Single crystal X-Ray diffraction 2

- Powder X-Ray diffraction 3

- In-situ high-temperature powder XRD 3

- TGA 3

- DSC 3

- Optical microscopy 3

- Scanning electron microscopy 3

2 Solubility tests 4

TableS1: Monomer salt formation tests and solubility tests of the monomer salt in 4 different solvents.

3 Polarization micrographs 5

Fig.S1: Polarization micrographs of single crystals of $\mathbf{3}$ and polymer particles 5

4 Photographs of monomer salt crystal with indexed facets $\quad 6$

Fig.S2: Indexed facets of a single crystal of monomer salt $3 \quad 6$

$5 \quad$ Hydrogen-bonding network within the crystal structure of $3 \quad 7$

TableS2: Hydrogen bond distances and angles within 3

Fig.S3: H-bonding network within the crystal structure of monomer salt $3 \quad 8$

6 Details of the crystal structure determination of $\mathbf{3} 9$

TableS3: Details of the crystal structure determination of 3

7 FT-IR-ATR analysis of monomers, monomer salt and polyimide particles $\quad \mathbf{1 0}$

Fig.S4: Superposition of FT-IR-ATR spectra of monomers and monomer salt $\quad 10$

Fig.S5: FT-IR-ATR spectrum of p-phenylene diamine 11

Fig.S6: FT-IR-ATR spectrum of pyromellitic acid $\quad 12$

Fig.S7: FT-IR-ATR spectrum of the monomer salt $\left[\mathrm{H}_{2} P D A^{2+} P M A^{2-}\right]$

Fig.S8: Superposition of FT-IR-ATR spectra of monomer salt 3 and the polyimide PPPI 14

8 Crystal structure data of 3 in cif format $\quad \mathbf{1 5}$

9 Calculation of volume change of crystal 3 to particles of $4 \quad \mathbf{1 6}$

10 References 16 


\section{Materials and Methods}

\section{a. Chemicals and experimental details}

PMA was freshly synthesized by hydrolysis of pyromellitic dianhydride ( $>98 \%$, MERCK). PDA, 97\%, and agarose were used as received from Sigma-Aldrich.

Gel growth of the monomer salt 3: $m(\mathrm{PMA})=50 \mathrm{mg}(0.2 \mathrm{mmol}), 2.5 \mathrm{wt} \%$ (relative to water) agarose and $5 \mathrm{~mL}$ distilled water were mixed, the mixture was heated to $85^{\circ} \mathrm{C}$, stirred until both agarose and PMA were completely dissolved, and then transferred to a test tube. This solution was allowed to slowly cool back to room temperature for gel formation. The cured gel was topped with $5 \mathrm{~mL}$ of an aqueous solution of PDA (mPDA $=5 \mathrm{mg} ; \mathrm{n}_{\mathrm{PDA}}=0.05 \mathrm{mmol}$; ratio $\mathrm{n}_{\mathrm{PDA}}: \mathrm{n}_{\mathrm{PMA}}=1: 4.2$ ), further topped with a layer of petroleum ether to avoid evaporation of water and thus a change in concentration, and additionally sealed with a cap to prevent any contamination. The test tube was then placed in a preheated oil bath $\left(60{ }^{\circ} \mathrm{C}\right)$. After $20 \mathrm{~h}$ the $\left[\mathrm{H}_{2} \mathrm{PDA}^{2+} \mathrm{PMA}^{2-}\right]$ crystals were recovered by dissolution of the agarose gel at $85^{\circ} \mathrm{C}$ and subsequent drying.

Solid-state polymerization of the monomer salts: The crystals were thermally transformed to polyimide particles via heating them up to $483 \mathrm{~K}$ in a round bottom flask under nitrogen atmosphere and keeping them at this temperature for $2 \mathrm{~h}$. The FTIR-spectrum of PPPI showed characteristic $\mathrm{C}=\mathrm{O}$ imide stretching modes at $1780 \mathrm{~cm}^{-1}$ (asymmetric) respectively $1720 \mathrm{~cm}^{-1}$ (symmetric) and the $\mathrm{C}-\mathrm{N}$ stretching band at 1365 $\mathrm{cm}^{-1}$.

Classical synthesis of PPPI: was carried out using $m$-cresol as solvent and isoquinoline as imidization catalyst according to reference [23].

\section{b. Characterization techniques}

FT-IR-ATR analysis was carried out using a Bruker Tensor 27 in ATR MicroFocusing MVPQL with a diamond crystal, and analyzed with Opus v4.0. The spectrum showed characteristic carboxylate-carboxylic acid hydrogen bonds at 3120 $\mathrm{cm}^{-1}$, arylamminium $\mathrm{N}-\mathrm{H}_{3}{ }^{+}$stretching modes at $2830 \mathrm{~cm}^{-1}$ (asym.) and $2580 \mathrm{~cm}^{-1}$ (sym.). Additionally, typical $\mathrm{COO}^{-}$stretching bands appear at $1605 \mathrm{~cm}^{-1}$ (asymmetric) respectively $1550 \mathrm{~cm}^{-1}$ (symmetric).

Single crystal X-ray diffraction analysis was carried out on a Bruker KAPPA APEX II diffractometer system using Saint Plus, Sadabs and Jana2006 software. The space group of $\left[\mathrm{H}_{2} \mathrm{PDA}^{2+} \mathrm{PMA}^{2-}\right]$ was determined to be monoclinic, $C 2 / c$ (No.15), with lattice parameters $a=12.6313(18) \AA, b=7.6720(12) \AA, c=16.025(3) \AA, \beta=$ $107.020(4)^{\circ}$ and a cell volume of $V=1484.93 A^{3}$. 
Powder X-ray diffraction analysis at room temperature was carried out on a PANalytical Xpert Pro MPD diffractometer system $\left[\mathrm{Cu} K \alpha_{1,2}\right.$ radiation $(\lambda=1.54060$ $\AA$, $1.54439 \AA$ ) equipped with an X-Celerator multichannel detector, Bragg Brentano geometry, silicon single crystal sample holder]. The diffraction pattern was recorded between 5 and $60^{\circ}(2 \theta)$ with $24.765 \mathrm{~s} /$ step and a step size of $0.02^{\circ}$. A powder diffraction pattern was calculated from the single crystal data using the program Mercury v3.3.

In situ high-temperature powder XRD was carried out using a PANalytical Xpert Pro MPD diffractometer system $\left[\mathrm{Cu} K \alpha_{1,2}\right.$ radiation $\left.(\lambda=1.54060 \AA, 1.54439 \AA)\right)$ equipped with an X-Celerator multichannel detector, Bragg Brentano geometry, Anton Paar HTK $1200 \mathrm{~N}$ oven]. The diffraction pattern was recorded between 10 and $70^{\circ}$ (2theta) with $240.03 \mathrm{~s} /$ step and a step size of $0.008^{\circ}$.

TGA experiments were performed under nitrogen flow with a Netzsch TG 209 using a heating rate of $10 \mathrm{~K} / \mathrm{min}$; the analysis software was NETZSCH Proteus (Version 4.3). TGA resulted in a polymerization onset $T_{p}$ of $205^{\circ} \mathrm{C}$.

DSC was performed on a Mettler Toledo DSC $823 \mathrm{a}$ with a heating rate of $5 \mathrm{~K} / \mathrm{min}$, resulting in a polymerization onset of about $210{ }^{\circ} \mathrm{C}$.

Optical microscopy was performed on a LEICA M 125 microscope, images were taken using the software LAS v3.7.

Scanning electron microscopy was carried out with a Quanta 200F FEI microscope. Typically the samples were measured at $5 \mathrm{kV}$, with a working distance of $9 \mathrm{~mm}$ and spot size 2.0. Prior to imaging, samples were loaded on carbon coated stubs and coated by sputtering with an $8 \mathrm{~nm}$ thick layer of $\mathrm{Au} / \mathrm{Pd}$ 60/40 alloy with a Quarum Q105T S sample preparation system. 


\section{Solubility tests}

In order to evaluate the solubility and salt formation in different solvents, we applied the following procedure: (1) PMA and PDA were immersed in the same solvent in two different vials; (2) The content of the vials was then mixed. If powder precipitated directly, the powder was isolated by filtration, dried and analyzed by FTIR-ATR to confirm the formation of $\left[\mathrm{H}_{2} \mathrm{PDA}^{2+} \mathrm{PMA}^{2-}\right]$. (3) The salt was then reimmersed in the same solvent and attempted to dissolve, at both room temperature and at reflux temperature (i.e. at the boiling point of the solvent). To test the solubility of the monomer salt in solvents where it hadn't formed; we used a monomer salt prepared in another solvent. The results of these tests are summarized in TableS1. The solubility tests indicate that a protic polar solvent is necessary to additionally provide protons for the acid-base reactions by which the salt is formed. In polar aprotic solvents, we found the formation of oligo- and polyamic acid (PAA) species in all cases. The salt itself dissolves in aprotic polar solvents (DMSO, DMF, DMAc, NMP); however in a reactive fashion: it directly reacts towards PAA species.

TableS1: Monomer salt formation tests and solubility tests of the monomer salt in different solvents. PMA = pyromellitic acid; PDA = para-phenylene-diamine; $R T=$ room temperature; $b p=$ boiling point; $\checkmark=$ soluble or monomer salt formation, $\boldsymbol{X}=$ monomer salt is insoluble, $\boldsymbol{}_{\text {PAA }}=$ no salt formation but formation of PAA. $\checkmark_{\text {PAA }}=$ monomer salt dissolves but directly forms oligo- and polyamicacids (PAAs).

\begin{tabular}{|c|c|c|c|c|c|c|}
\hline Solvent & $\begin{array}{l}\text { PMA } \\
\text { alone }\end{array}$ & $\begin{array}{l}\text { PDA } \\
\text { alone }\end{array}$ & $\begin{array}{l}\text { Salt } \\
\text { formation } \\
\text { upon } \\
\text { mixing }\end{array}$ & $\begin{array}{l}\text { Salt } \\
\text { soluble } \\
\text { in } \\
\text { solvent } \\
\text { at } R T\end{array}$ & $\begin{array}{l}\text { Salt } \\
\text { soluble } \\
\text { in } \\
\text { solvent } \\
\text { at } b p\end{array}$ & $\begin{array}{l}b p \text { of } \\
\text { solvent }\end{array}$ \\
\hline $\begin{array}{l}\text { Dimethylsulfoxide } \\
\text { (DMSO) }\end{array}$ & $\checkmark$ & $\checkmark$ & $\sqrt{\text { PAA }}$ & $\sqrt{\text { PAA }}$ & $\sqrt{\text { PAA }}$ & $189^{\circ} \mathrm{C}$ \\
\hline $\begin{array}{l}\text { Dimethylformamide } \\
\text { (DMF) }\end{array}$ & $\checkmark$ & $\sqrt{ }$ & $\sqrt{\text { PAA }}$ & $\sqrt{\mathrm{PAA}}$ & $\sqrt{\text { PAA }}$ & $153^{\circ} \mathrm{C}$ \\
\hline $\begin{array}{l}\text { Dimethylacetamide } \\
\text { (DMAc) }\end{array}$ & $\checkmark$ & $\checkmark$ & $\sqrt{\text { PAA }}$ & $\sqrt{\text { PAA }}$ & $\sqrt{\text { PAA }}$ & $165^{\circ} \mathrm{C}$ \\
\hline $\begin{array}{l}\mathrm{N}- \\
\text { Methylpyrrolidone } \\
\text { (NMP) }\end{array}$ & $\checkmark$ & $\checkmark$ & $\sqrt{\text { PAA }}$ & $\sqrt{\text { PAA }}$ & $\sqrt{\text { PAA }}$ & $202^{\circ} \mathrm{C}$ \\
\hline Water & $\checkmark$ & $\checkmark$ & $\checkmark$ & $x$ & $x$ & $100^{\circ} \mathrm{C}$ \\
\hline Methanol & $\checkmark$ & $\checkmark$ & $\checkmark$ & $x$ & $x$ & $65^{\circ} \mathrm{C}$ \\
\hline Ethanol & $\checkmark$ & $\checkmark$ & $\sqrt{ }$ & $x$ & $x$ & $78^{\circ} \mathrm{C}$ \\
\hline n-Propanol & $\checkmark$ & $\checkmark$ & $\sqrt{ }$ & $x$ & $x$ & $97^{\circ} \mathrm{C}$ \\
\hline iso-propanol & $\checkmark$ & $\checkmark$ & $\sqrt{ }$ & $x$ & $x$ & $83^{\circ} \mathrm{C}$ \\
\hline$n$-Butanol & $\checkmark$ & $\checkmark$ & $\sqrt{ }$ & $x$ & $x$ & $118^{\circ} \mathrm{C}$ \\
\hline iso-Butanol & $\checkmark$ & $\checkmark$ & $\checkmark$ & $x$ & $x$ & $108^{\circ} \mathrm{C}$ \\
\hline sec-Butanol & $\checkmark$ & $\sqrt{ }$ & $\sqrt{ }$ & $x$ & $x$ & $98^{\circ} \mathrm{C}$ \\
\hline tert-Butanol & $\sqrt{ }$ & $\sqrt{ }$ & $\sqrt{ }$ & $x$ & $x$ & $82^{\circ} \mathrm{C}$ \\
\hline
\end{tabular}




\section{Polarization micrographs of gel-grown monomer salt single crystals}

Fig.S1A-D shows micrographs of monomer salt single crystals viewed through an optical polarizer (polarizer is turned between panels $\mathrm{A}$ and $\mathrm{B}$, and $\mathrm{C}$ and D). It becomes clear that the single crystals of the monomer salt $\left[\mathrm{H}_{2} \mathrm{PDA}^{2+} \mathrm{PMA}^{2-}\right]$ show privileged directions, as all crystals oriented along $c^{*}$ (i.e. biggest facet of the crystal parallel to the microscope plate) change between extinction and letting light pass through (bright appearance) between $\mathrm{A}$ and $\mathrm{B}$, and $\mathrm{C}$ and $\mathrm{D}$. Once polymerized, the particles are nontransparent to light: Fig.S1E-F shows monomer salt single crystals (left) and polyimide particles (right). The micrograph with impingent light (Fig.S1E) shows that the salt crystals are transparent, whereas the polyimide particles are turbid and darker than the salt crystals. When viewed through a polarizer in transmission mode (Fig.S1F), the PI particles are not visible as they aren't transparent to light.
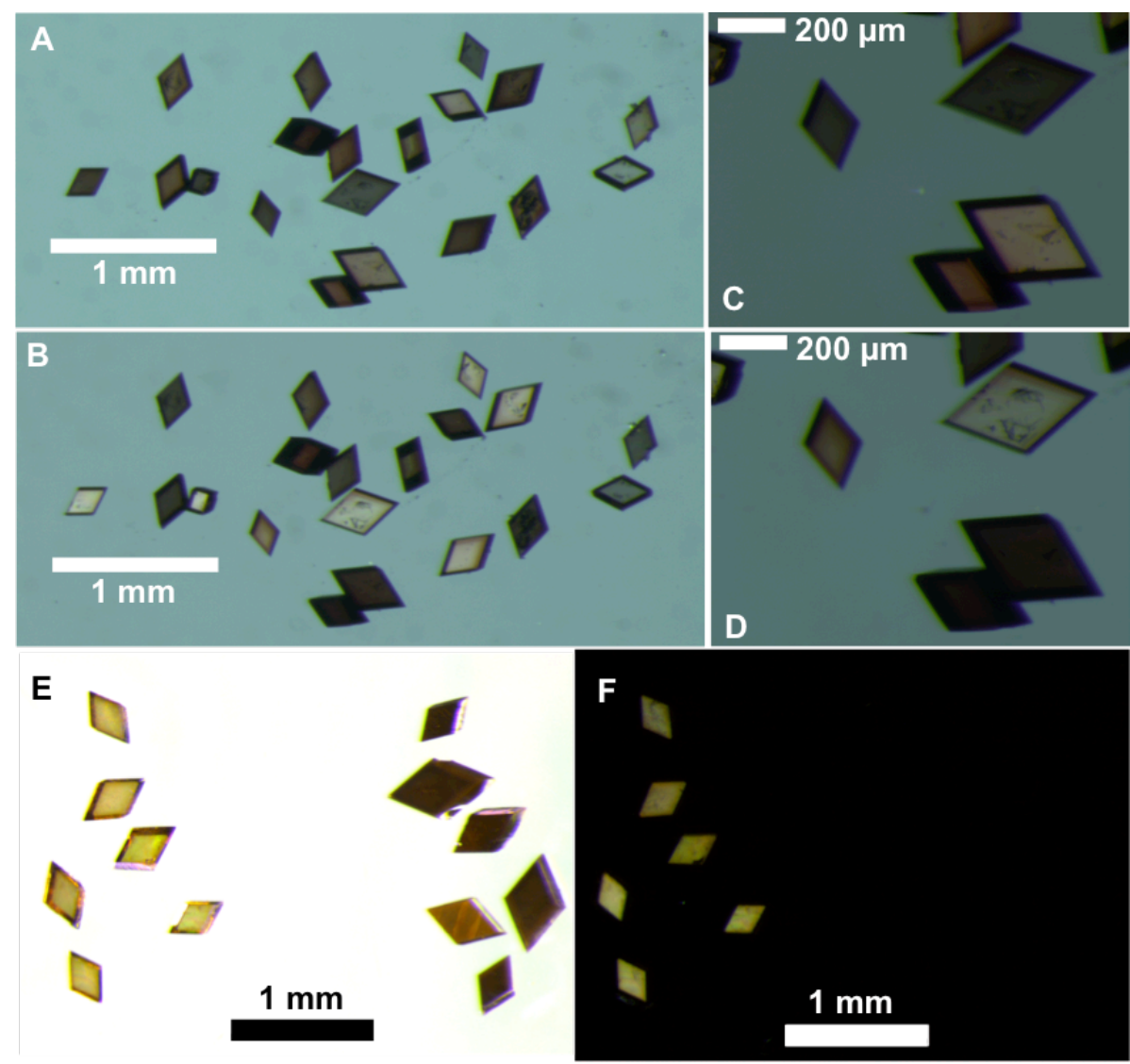

Fig.S1: Polarization micrographs of monomer salt single crystals and polymer particles. A-B: Monomer salt single crystals viewed in transmission mode through a polarizer; polarizer is turned between A and B. C-D: Zoom into A and B, respectively. E-F: Monomer salt crystals (left) vs. polyimide particles (right); E: impingent light; F: transmission mode with polarizer. 


\section{Photographs of monomer salt crystal with indexed facets}

Fig.S2 shows photographs of a monomer salt single crystal of $\mathbf{3}$ in the singlecrystal diffractometer, with indexed facets (imaged from different sides).
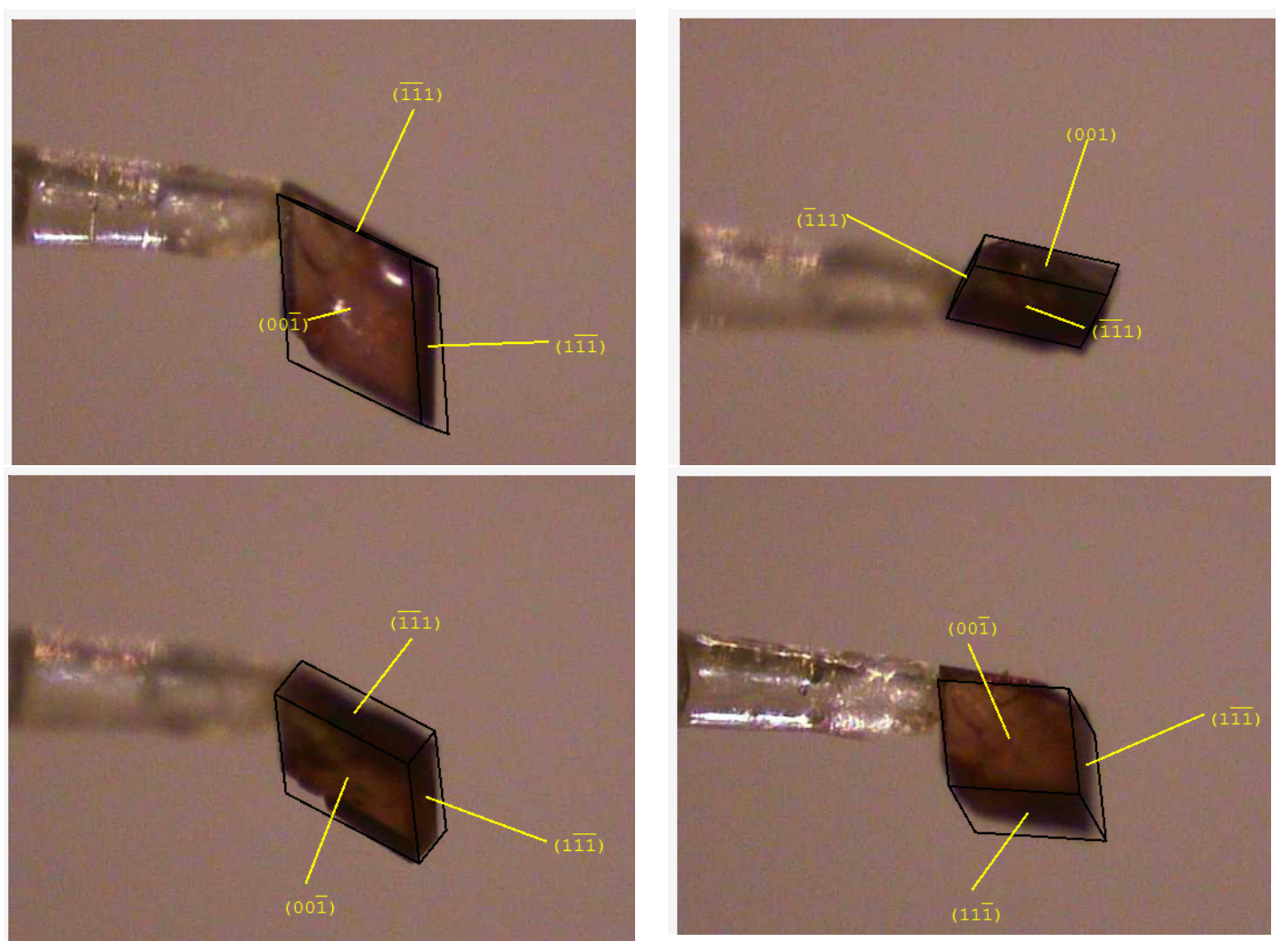

Fig.S2: Indexed facets of single crystal of the monomer salt 3. Single crystal diffraction was performed using a Bruker KAPPA APEX II diffractometer system The crystal was imaged and indexed with the software APEX3 by Bruker. 
5 Hydrogen-bonding network within the crystal structure of $\mathbf{3}$

TableS2 contains all hydrogen bond distances and lengths within the crystal structure of monomer salt 3 . All distances and angles were extracted using the software Mercury (CSD).

TableS2: Hydrogen bond $\left(A^{\cdots} \mathrm{H}-\mathrm{D}\right)$ distances and angles within monomer salt $3 . \mathrm{A}=$ acceptor, $\mathrm{D}=$ donor, $d=$ distance, $\angle=$ angle. Displayed on top are the two organic ions PMA ${ }^{2-}$ (left) and $\mathrm{H}_{2} \mathrm{PDA}^{2+}$ (right) with H-bonds (green dotted lines), bond distances (green) and naming of the atoms (white font with black lining). Note that both molecules bear a center of point symmetry in the center of the aromatic ring; the therefrom arising second half of $\mathrm{H}$-bonds of each molecule is not shown for reasons of visibility. Atom color code: red = oxygen, grey $=$ carbon, blue $=$ nitrogen, white $=$ hydrogen.
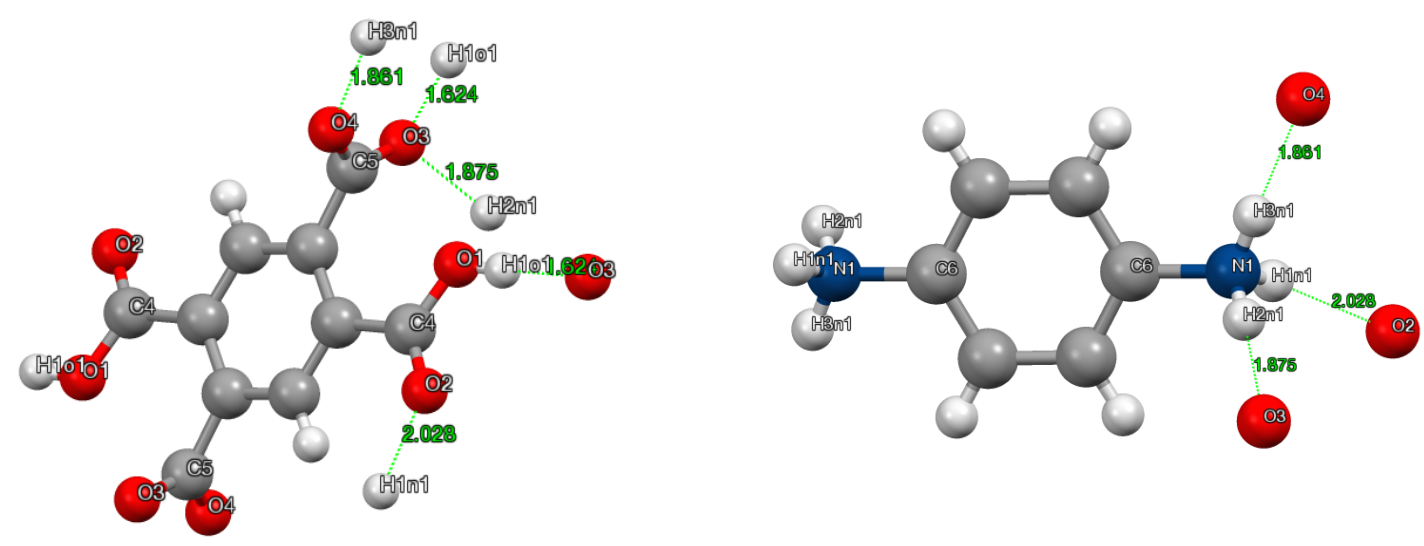

\begin{tabular}{|c|c|c|}
\hline $\mathbf{A}^{\cdots} \mathbf{H}$ & $d\left(\mathbf{A}^{\cdots} \mathbf{H}\right)$ in $[\AA ̊]$ & $\angle\left(\mathbf{A}^{\cdots} \cdot \mathbf{H}-\mathbf{D}\right)$ in $\left[{ }^{\circ}\right]$ \\
\hline $\mathrm{O} 2 \cdots \mathrm{H} 1 \mathrm{n} 1$ & 2.028 & $150.20(\mathrm{O} 2 \cdots \mathrm{H} 1 \mathrm{n} 1-\mathrm{N} 1)$ \\
\hline $\mathrm{O} 3{ }^{\cdots} \mathrm{H} 1 \mathrm{o} 1$ & 1.624 & $176.72\left(\mathrm{O} 3{ }^{\cdots} \mathrm{H} \mathrm{ol} 1-\mathrm{O} 1\right)$ \\
\hline $\mathrm{O} 3{ }^{\cdots} \mathrm{H} 2 \mathrm{n} 1$ & 1.875 & $177.72\left(\mathrm{O} 3{ }^{\cdots} \mathrm{H} 2 \mathrm{n} 1-\mathrm{N} 1\right)$ \\
\hline $\mathrm{O} 4{ }^{\cdots} \mathrm{H} 3 \mathrm{n} 1$ & 1.861 & $173.34(\mathrm{O} 4 \cdots \mathrm{H} 3 \mathrm{n} 1-\mathrm{N} 1)$ \\
\hline
\end{tabular}



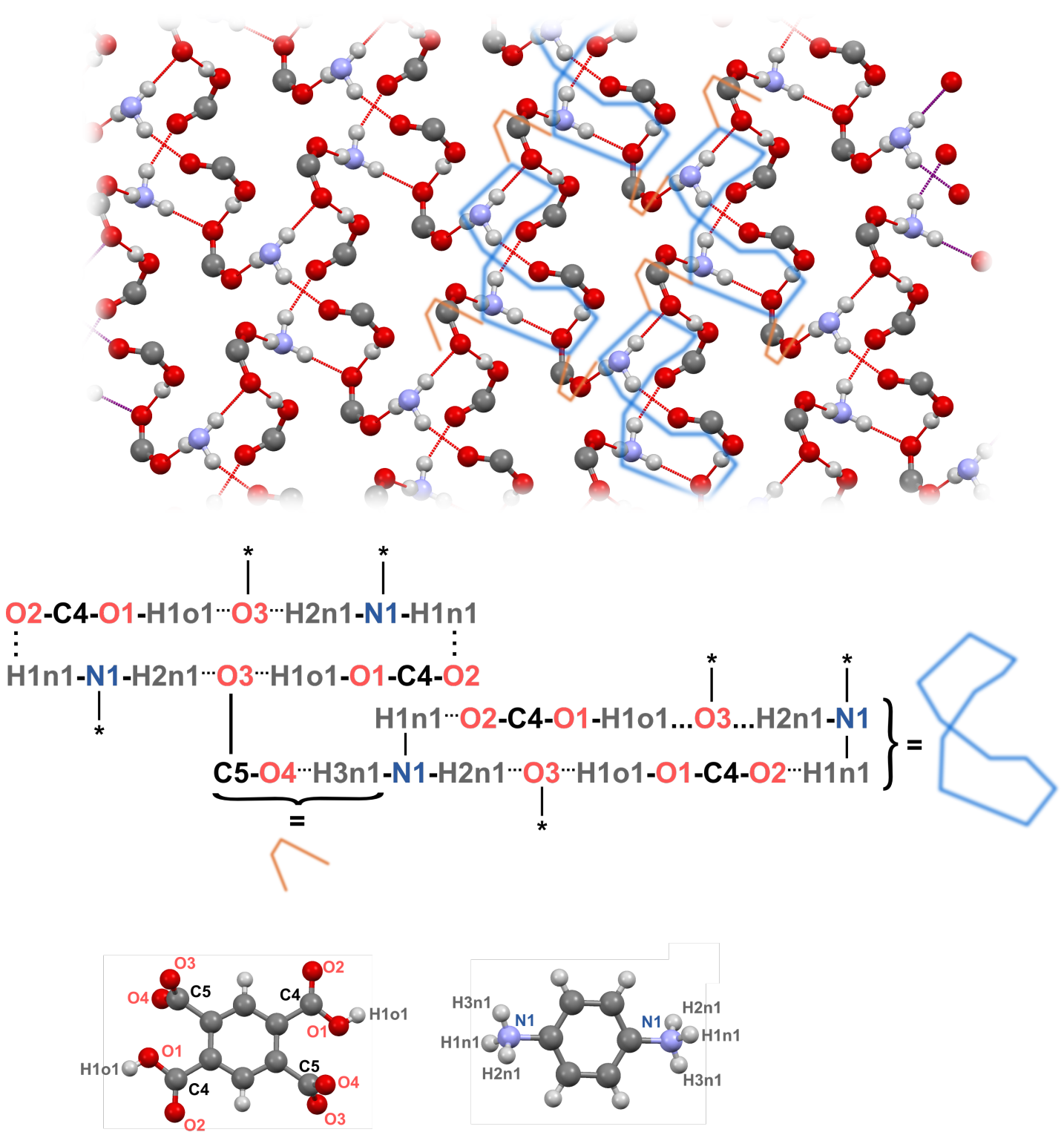

Fig.S3: H-bonding network within the crystal structure of monomer salt 3. Top: Schematic of the Hbonding layer viewed onto the ab-plane of the unit cell. Atoms not participating in the H-bonding network are omitted for clarity, with the exception of carbon atoms that are part of the carboxylate and carboxylic acid groups at $\mathrm{PMA}^{2-}$ (i.e. $\mathrm{C} 4$ and $\mathrm{C} 5$ ). The pattern contains two structural units: 16membered twisted rings (blue lines) that are bridged by $\mathrm{C} 5-\mathrm{O} 4$ (orange line). Bottom: Key two the Hbonding pattern. Shown are the two ions with atom code and the H-bonding pattern displayed as succession of all atoms in the structural units of the pattern. Atom color code: Atom color code: red $=$ oxygen, grey $=$ carbon, blue $=$ nitrogen, white $=$ hydrogen . 
6 Details of the crystal structure determination of $\mathbf{3}$

TableS3: Details for the crystal structure determinations of $\left[\mathrm{H}_{2} \mathrm{PDA}^{2+} \mathrm{PMA}^{2-}\right]$.

\begin{tabular}{|c|c|}
\hline & {$\left[\mathrm{H}_{2} \mathbf{P D A}^{2+} \mathbf{P M A}^{2-}\right]$} \\
\hline formula & $\mathrm{C}_{8} \mathrm{H}_{7} \mathrm{NO}_{4}$ \\
\hline fw & 181.1 \\
\hline cryst.size, $\mathrm{mm}$ & $0.33 \times 0.19 \times 0.03$ \\
\hline color, shape & clear colourless rhombic prism \\
\hline crystal system & monoclinic \\
\hline space group & $C 2 / c($ no. 15$)$ \\
\hline$a, \AA$ & $12.6313(18)$ \\
\hline$b, \AA$ & $7.6720(12)$ \\
\hline$c, \AA$ & $16.025(3)$ \\
\hline$\beta,^{\circ}$ & $107.020(4)$ \\
\hline$V, \AA^{3}$ & $1484.9(4)$ \\
\hline$T, \mathrm{~K}$ & 100 \\
\hline Z,Z' & 8,1 \\
\hline$\rho_{\text {calc }}, \mathrm{g} \mathrm{cm}^{-3}$ & 1.6200 \\
\hline$\mu, \mathrm{mm}^{-1}(\mathrm{MoK} \alpha)$ & 0.133 \\
\hline$F(000)$ & 752 \\
\hline absorption corrections, $T_{\min }-T_{\max }$ & multi-scan, $0.97-1.00$ \\
\hline$\theta$ range, deg & $2.66-33.17$ \\
\hline no. of rflns measd & 35648 \\
\hline$R_{\text {int }}$ & 0.0368 \\
\hline no. of rflns unique & 2842 \\
\hline no. of rflns $I>3 \sigma(I)$ & 2352 \\
\hline no. of params / restraints & $134 / 1$ \\
\hline$R(I>3 \sigma(I))^{\mathrm{a}}$ & 0.0324 \\
\hline$R$ (all data) & 0.0415 \\
\hline$w R(I>3 \sigma(I))$ & 0.0466 \\
\hline$w R$ (all data) & 0.0470 \\
\hline GooF & 2.65 \\
\hline $\begin{array}{l}\text { Diff.Four.peaks } \\
\min / \max , \mathrm{e} \AA^{-3}\end{array}$ & $-0.25 / 0.43$ \\
\hline CCDC no. & 1436741 \\
\hline
\end{tabular}




\section{FT-IR-ATR}

Due to the insolubility of the monomer salt $\left[\mathrm{H}_{2} \mathrm{PDA}^{2+} \mathrm{PMA}^{2-}\right]$ without further reaction to e.g. PAAs in any tested solvent, solution characterization techniques (such as solution NMR), cannot be used. Infrared-spectroscopy is however ideally suited to analyze the formation of monomer salts of the diamminium-dicarboxylate dicarboxylic acid type. ${ }^{[16-17, \mathrm{~S} 1]}$ Fig.S4 shows an overlay of the FT-IR-ATR spectra of the starting compounds ( $p$-phenylene diamine, blue; pyromellitic acid, red), with the salt $\left[\mathrm{H}_{2} \mathrm{PDA}^{2+} \mathrm{PMA}^{2-}\right]$ (black).

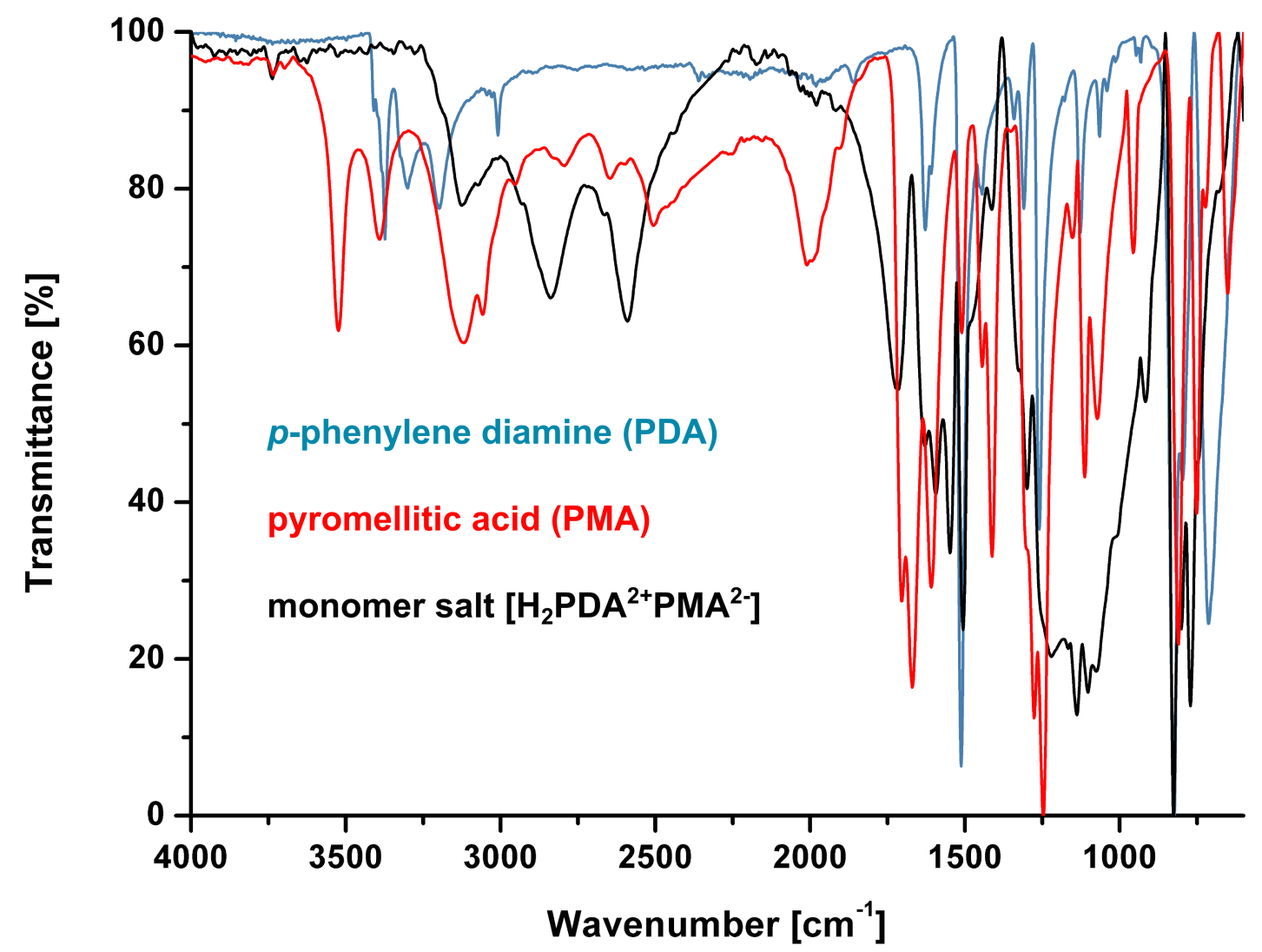

Fig.S4: Superposition of FT-IR-ATR spectra of monomers and monomer salt. Pyromellitic acid (PMA, red), $p$-phenylene diamine (PDA, blue) and monomer salt $\left(\left[\mathrm{H}_{2} \mathrm{PDA}^{2+} \mathrm{PMA}^{2-}\right]\right.$, black).

For clarity, all three spectra are displayed separately (Fig.S5-S7). $p$-PDA (blue in Fig.S4; Fig.S5) shows the typical N-H stretching modes of aromatic primary amines at $3374 \mathrm{~cm}^{-1}, 3296 \mathrm{~cm}^{-1}$ and primary amine $\mathrm{H}$-bonding at $3200 \mathrm{~cm}^{-1}$. Moreover, the N-H scissoring mode appears at $1628 \mathrm{~cm}^{-1}$, and the C-N stretching mode is attributed to the band at $1261 \mathrm{~cm}^{-1}$. Also, the $\mathrm{NH}_{2}$ wagging and twisting bands at $825 \mathrm{~cm}^{-1}$ and $741 \mathrm{~cm}^{-1}$, respectively are present. The FT-IR-ATR spectrum corresponds very well to previously reported IR-spectra of the same compound (see insert in Fig.S5). ${ }^{[\mathrm{S} 2]}$ 


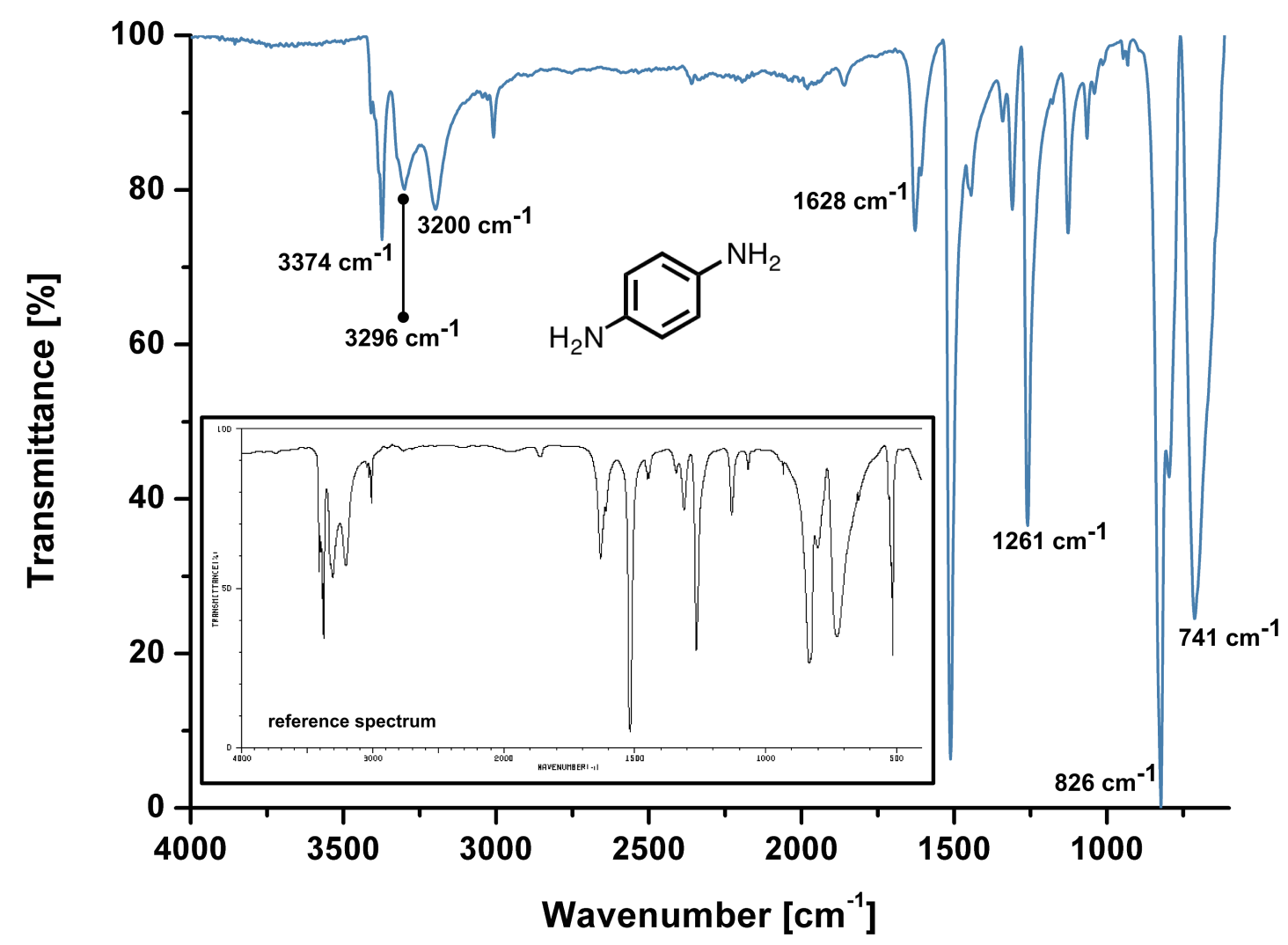

Fig.S5: FT-IR-ATR spectrum of p-phenylene diamine (PDA, molecular formula depicted). Spectrum of PDA (blue); insert $=$ reference spectrum ${ }^{[\mathrm{S} 2]}$. Attributed bands: $3374 \mathrm{~cm}^{-1}$ and $3296 \mathrm{~cm}^{-1}(\mathrm{~N}-\mathrm{H}$ stretching mode of primary aromatic amines); $3200 \mathrm{~cm}^{-1}$ (intermolecular H-bonding mode primary amines); $1628 \mathrm{~cm}^{-1}$ ( $\mathrm{NH}_{2}$ scissoring vibration), $1261 \mathrm{~cm}^{-1}$ (aromatic C-N stretching), $825 \mathrm{~cm}^{-1}\left(\mathrm{NH}_{2}\right.$ wagging), $741 \mathrm{~cm}^{-1}\left(\mathrm{NH}_{2}\right.$ twisting).

The pure tetra-carboxylic acid PMA (red in Fig.S4; Fig. S6) features the carboxylic acid $\mathrm{O}-\mathrm{H}$ stretching at $3528 \mathrm{~cm}^{-1}$, and the $\mathrm{O}-\mathrm{H}$ bending modes at $1414 \mathrm{~cm}^{-}$ ${ }^{1}$ and at $949 \mathrm{~cm}^{-1}$. At $3400 \mathrm{~cm}^{-1}$ and $3130 \mathrm{~cm}^{-1}$, we find the stretching modes of the intermolecular carboxylic acid dimer. The carboxylic acid carbonyl $\mathrm{C}=\mathrm{O}$ stretching is present at $1714 \mathrm{~cm}^{-1}$, and its C-O stretching mode at $1280 \mathrm{~cm}^{-1}$. Here too, the FT-IRATR spectrum corresponds well to previously reported spectra (see insert; area from $\left.4000-1800 \mathrm{~cm}^{-1}\right) .^{[\mathrm{S} 3]}$ The region $2600-2000 \mathrm{~cm}^{-1}$ (blue frame) correspond accurately to the literature pattern: whereas the mode centered around $\sim 2500 \mathrm{~cm}^{-1}$ can be attributed to the $\mathrm{O}-\mathrm{H}$ stretching, we are to date not sure about the molecular origin of the mode centered around $\sim 2000 \mathrm{~cm}^{-1}$. Our current hypothesis is that this band might be an aromatic summation mode (combination mode), as the combination modes of lower wavenumber vibrations of substituted benzene are typically found at $2000-1700 \mathrm{~cm}^{-1} \cdot{ }^{[\mathrm{S} 4]}$ 


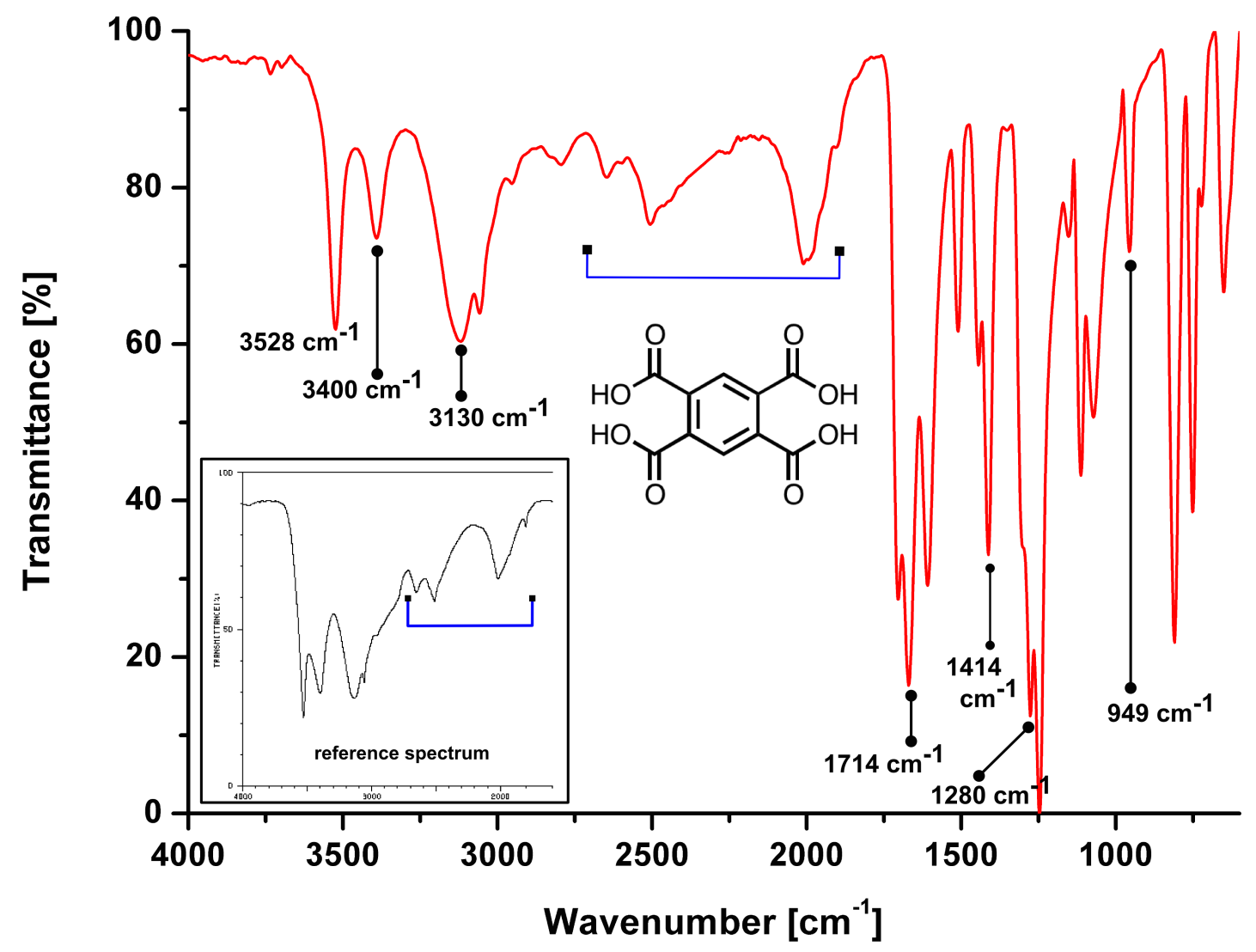

Fig.S6: FT-IR-ATR spectrum of pyromellitic acid (PMA, molecular formula depicted). Spectrum of PMA (red); insert $=$ reference spectrum ${ }^{[\mathrm{S} 3]}$. Attributed bands: $3528 \mathrm{~cm}^{-1}(\mathrm{O}-\mathrm{H}$ stretching mode $) ; 3400$ $\mathrm{cm}^{-1}, 3130 \mathrm{~cm}^{-1}$ (stretching modes carboxylic acid dimer); $1714 \mathrm{~cm}^{-1}$ (C=O stretching mode), $1414 \mathrm{~cm}^{-}$ ${ }^{1}$ (O-H bending, in plane), $1280 \mathrm{~cm}^{-1}$ (C-O stretching), $949 \mathrm{~cm}^{-1}$ (O-H bending, out of plane).

The monomer salt $\left[\mathrm{H}_{2} \mathrm{PDA}^{2+} \mathrm{PMA}^{2-}\right]$ results from the acid-base reaction between PDA and PMA in water. The FT-IR-ATR spectrum of the salt (black in Fig.S4; Fig.S7) is clearly different from the two starting monomers. It features: the $\mathrm{CO}_{2}^{-\cdots} \mathrm{HO}_{2} \mathrm{C}$ hydrogen bonding at $3120 \mathrm{~cm}^{-1}$, the two broad aryl-amminium vibration modes at $2830 \mathrm{~cm}^{-1}$ (asymmetric) and $2580 \mathrm{~cm}^{-1}$ (symmetric), the characteristic carboxylate modes at $1605 \mathrm{~cm}^{-1}$ (asymmetric) and $1550 \mathrm{~cm}^{-1}$ (symmetric). Moreover, the spectrum shows the $\mathrm{C}=\mathrm{O}$ stretching band of carboxylic acids at $1717 \mathrm{~cm}^{-1}$, as only two of the four acid groups in PMA get deprotonated. This band is slightly shifted with respect to pure PMA $\left(1714 \mathrm{~cm}^{-1}\right)$. The other characteristic modes of both PDA and PMA disappear entirely. The FT-IR-ATR spectrum corresponds well to the previously reported one. ${ }^{[22]}$ 


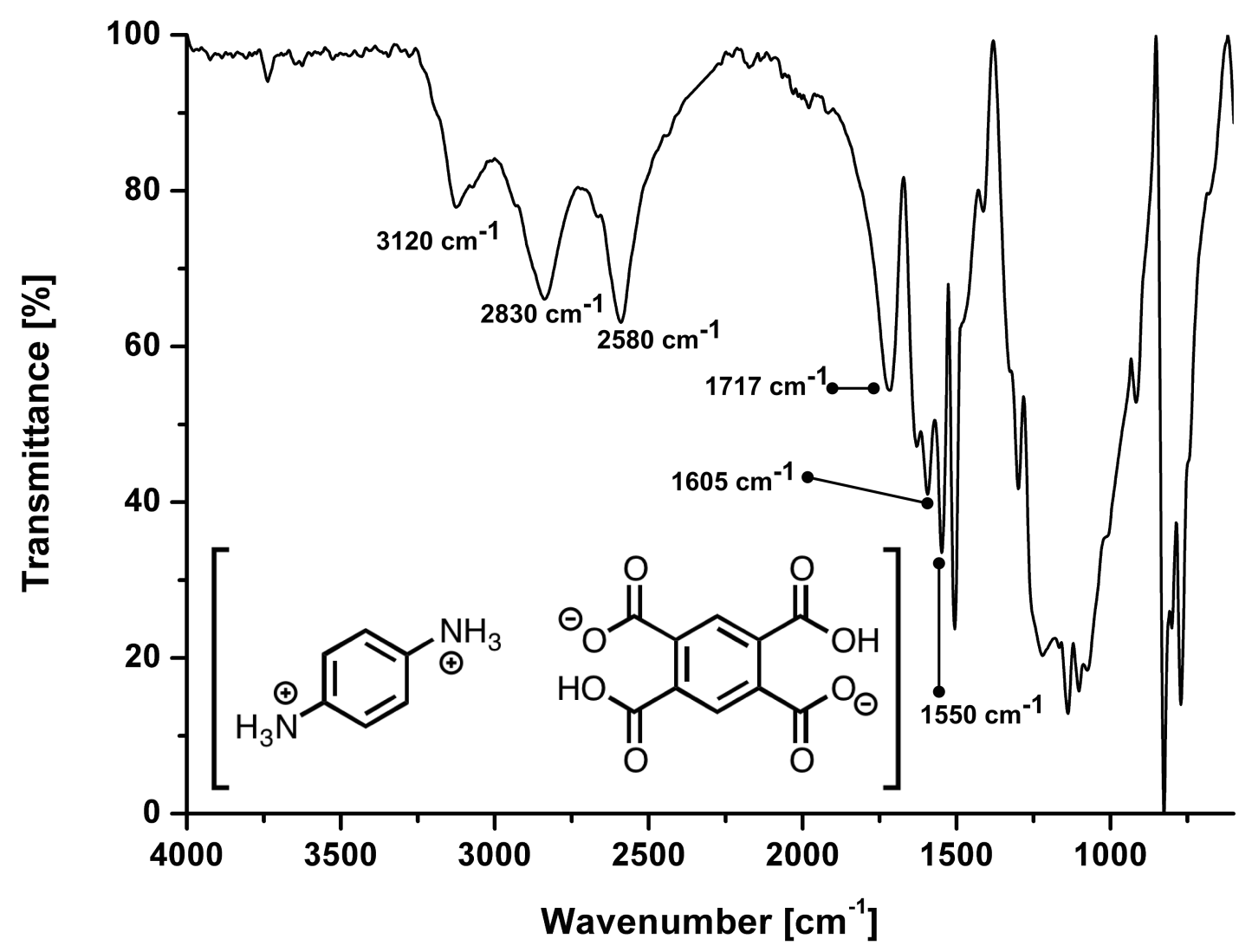

Fig.S7: FT-IR-ATR spectrum of the monomer salt $\left[\mathrm{H}_{2} \boldsymbol{P D} \boldsymbol{A}^{2+} \boldsymbol{P M} \boldsymbol{A}^{2-}\right]$ (molecular formula depicted). Spectrum of the salt in black; Attributed bands: $3120 \mathrm{~cm}^{-1}\left(\mathrm{CO}_{2}{ }^{-\cdots} \mathrm{HO}_{2} \mathrm{C}\right.$ dimer $) ; 2830 \mathrm{~cm}^{-1}$ and 2580 $\mathrm{cm}^{-1}$ (aryl- $\mathrm{NH}_{3}^{+}$modes; asymmetric and symmetric, respectively); $1717 \mathrm{~cm}^{-1}$ (carboxylic acid $\mathrm{C}=\mathrm{O}$ stretching mode); $1605 \mathrm{~cm}^{-1}$ and $1550 \mathrm{~cm}^{-1}\left(\mathrm{CO}_{2}^{-}\right.$stretching modes; asymmetric and symmetric, respectively).

FigureS8 shows a superposition of the FT-IR-ATR spectra of monomer salt $\left[\mathrm{H}_{2} \mathrm{PDA}^{2+} \mathrm{PMA}^{2-}\right]$ (black) and resulting polyimide PPPI (violet) after solid-state polycondensation. The salt bands described above entirely disappear, whereas the three classical modes of cyclic imides appear: the asymmetric and symmetric $\mathrm{C}=\mathrm{O}$ stretching modes at $1780 \mathrm{~cm}^{-1}$ and $1720 \mathrm{~cm}^{-1}$, and the C-N stretching mode at 1365 $\mathrm{cm}^{-1}$. The absence of any modes related to end-groups $\left(\mathrm{NH}_{2}\right.$ and $\mathrm{CO}_{2}^{-}$or $\left.\mathrm{CO}_{2} \mathrm{H}\right)$ indicates a fully condensed product of very high molecular weight. Here again, the FT-IR-ATR spectrum of PPPI corresponds well to the previously reported one. ${ }^{[25]}$ 


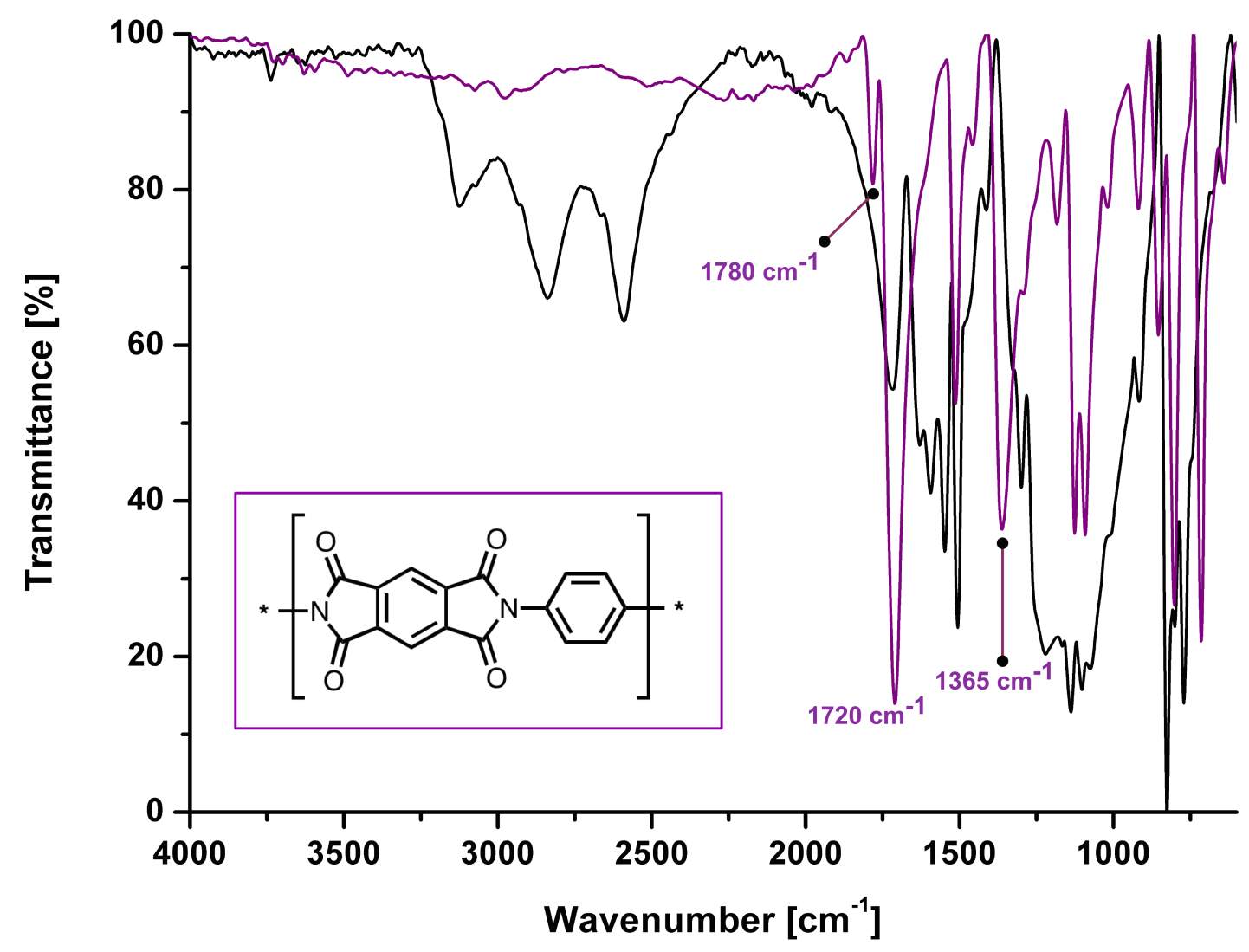

Fig.S8: Superposition of FT-IR-ATR spectra of the monomer salt $\left[\mathrm{H}_{2} \mathrm{PDA}{ }^{2+} \mathrm{PMA}^{2-}\right]$ and the polyimide PPPI (molecular formula of PPPI depicted). Spectrum of the polymer in violet; Attributed bands: $1780 \mathrm{~cm}^{-1}$ and $1720 \mathrm{~cm}^{-1}\left(\mathrm{C}=\mathrm{O}\right.$ modes; asymmetric and symmetric, respectively); $1365 \mathrm{~cm}^{-1}$ (cyclic imide $\mathrm{C}-\mathrm{N}$ stretching modes). 
$\mathbf{8}$ Crystal structure data of $\mathbf{3}$ (CCDC 1436741) in cif format

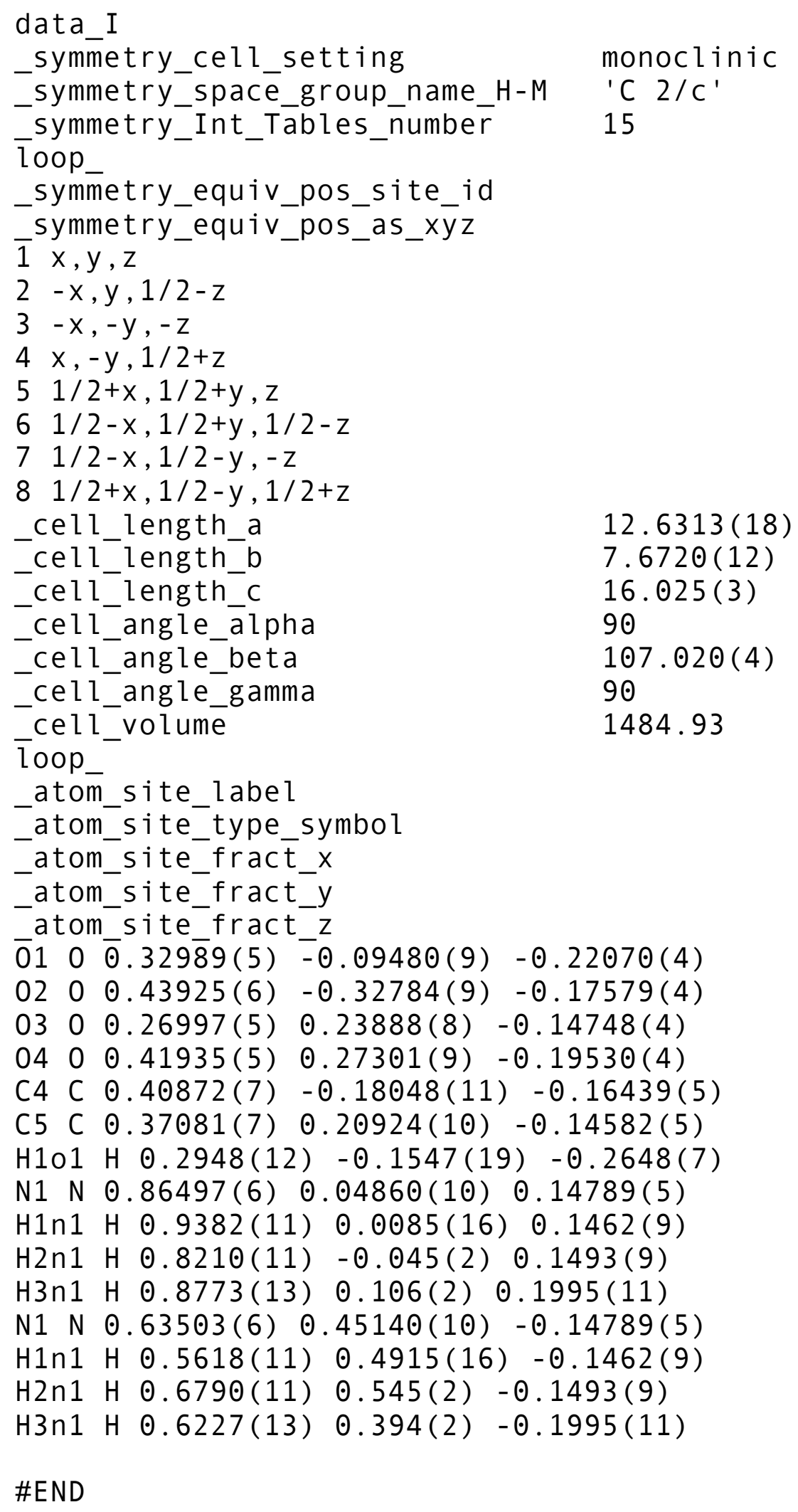




\section{Calculation of volume change of crystal 3 to particles of 4}

The crystal density $\rho$ of monomer salt $\mathbf{3}$ is

and the crystal density of PPPI 4 is

$$
\rho(3)=1.62 \frac{g}{\mathrm{~cm}^{3}}
$$

$$
\rho(4)=1.73 \frac{\mathrm{g}}{\mathrm{cm}^{3}}
$$

Suppose that

(i) there is no additional porosity created by the formation of $\mathrm{H}_{2} \mathrm{O}$

(ii) all formed $\mathrm{H}_{2} \mathrm{O}$ has entirely left the particles

(iii) and that the density of 3 and 4 is fully described by the crystal density, then the change in density upon SSP is

$$
100-\left(\frac{\rho(4)}{\rho(3)}\right) \cdot 100=100-\left(\frac{1.73}{1.62}\right) \cdot 100 \approx 6.79 \% \approx 7 \%
$$

Volume $V$ is given by

$$
V=\frac{m}{\rho}
$$

with $m=$ mass. As determined by TGA, the change of mass upon SSP is $20 \%$, thus one can express $m(\mathbf{4})$ as

$$
m(4)=0.8 \cdot m(3)
$$

Hence the change in volume of crystals of $\mathbf{3}$ when polymerized to particles of $\mathbf{4}$ equals to

$$
V(\mathbf{4})=\frac{m(\mathbf{4})}{\rho(\mathbf{4})}=\frac{0.8 \cdot m(\mathbf{3})}{1.07 \cdot \rho(3)} \approx 0.75 \approx 25 \%
$$

By simplifying to a cubic shape with $a=$ edge, the expected change in the edge of a particle for a volume change of $25 \%$ would be

$$
\Delta a=\sqrt[3]{\Delta} V \approx 0.91 \approx 9 \%
$$

The gel-grown single crystals of 3 are $c a$. $200-300 \mu \mathrm{m}$ in size, thus a change of $9 \%$ would be expected in the range of $20-30 \mu \mathrm{m}$.

\section{References}

[S1] Bell, V.L. "Heteroaromatic Polymers via Salt Intermediates" Polym. Lett. 5, 941-946 (1967).

[S2] Spectral Database of Organic Compounds (SDBS) of the Japanese National Institute of Advanced Science and Technology (AIST); SDBS Substance No. 1131; http://sdbs.db.aist.go.jp/sdbs/cgi-bin/direct frame disp.cgi?sdbsno=1131

[S3] Spectral Database of Organic Compounds (SDBS) of the Japanese National Institute of Advanced Science and Technology (AIST); retrieved from CAS SciFinder search term: $\mathrm{CAS}=89-05-4$

[S4] Smith, B.C. "Infrared spectral interpretations: a systematic approach", CRC Press LLC, Florida (1999). 